Preliminary draft

Not for quotation nor citation

Revised July 16, 2007

without an author's permission

\title{
A TEST OF THE CRITICAL PERIOD HYPOTHESIS \\ FOR LANGUAGE LEARNING*
}

\author{
By \\ Barry R. Chiswick \\ Department of Economics \\ University of Illinois at Chicago \\ and \\ IZA-Institute for the Study of Labor \\ and \\ Paul W. Miller \\ Business School \\ University of Western Australia
}

Postal Addresses:

Barry R. Chiswick

Department of Economics

University of Illinois at Chicago

601 S. Morgan St. (M/C 144)

Chicago, IL 60607-7121
Paul W. Miller

Department of Economics

University of Western Australia

Perth, Western Australia

Australia

Keywords: Immigrants, Second Language Learning, Age, Critical Period Hypothesis

JEL Codes: F220, J150 


\title{
A TEST OF THE CRITICAL PERIOD HYPOTHESIS FOR LANGUAGE LEARNING
}

\begin{abstract}
A critical period for language learning is often defined as a sharp decline in learning outcomes with age. This study examines the relevance of the critical period for English speaking proficiency among immigrants in the US. It uses microdata from the 2000 US Census, a model of language acquisition, and a flexible specification of an estimating equation based on 64 age-at-migration dichotomous variables. Self-reported English speaking proficiency among immigrants declines more-or-less monotonically with age at migration, and this relationship is not characterized by any sharp decline or discontinuity that might be considered consistent with a "critical" period. The findings are robust across the various immigrant samples, and between the genders. (110 words).
\end{abstract}


Revised July 2007

\section{A TEST OF THE CRITICAL PERIOD HYPOTHESIS FOR LANGUAGE LEARNING}

\section{INTRODUCTION}

It is generally agreed that learning a language is easier for younger than older people, where the measure of success is ultimate achievement (see, for example, LarsenFreeman and Long, 1991, Scovel, 2000, Hyltenstam and Abrahamsson, 2003). ${ }^{1}$ Many studies of age-related language acquisition have hypothesized a critical learning period. At ages below the critical period language learning can lead to native-like proficiency, or language acquisition can occur simply through exposure rather than through tutoring, or language skill acquisition is simply easier. At ages above the critical period learning a second language is much more difficult. A critical period should, according to Hakuta, Bialystok and Wiley (2003, p.31), be associated with "a significant change in learning outcome, not merely a monotonic decline with age”. The empirical research on agerelated differences has examined both first language and second language acquisition. A critical period in first language (mother tongue) acquisition does not necessarily imply a similar period in second language acquisition (Bialystok, 1997, p.118).

The literature has provided a number of theoretical models for the age-related differences, using explanations that are largely biologically-based (the brain's loss of plasticity) and cognitive-based (where problem solving and other learning approaches

decline in effectiveness gradually with age). ${ }^{2}$ The distinguishing feature of the cognitivebased explanations is that language proficiency declines reasonably smoothly with the age at which learning commences, whereas the biological-based accounts have a markedly different relationship between the age at which learning or exposure commences and the long-run attainment. That is, there is a discontinuity in the negative relation between age and language learning.

There have been many attempts to demark the critical period. Arriving at consensus findings from this research is difficult, however, as "...there is great variation among researchers on which age spans they use to divide up their subjects, and there may be multiple critical periods at varying age levels for different linguistic modalities...” 
Scovel (2000, p.215). Thus, a reasonably wide range of estimates have been advanced in the literature: for example, up to around 9 years by Penfield and Roberts (1959) and ages 2 to puberty by Lenneberg (1967). Krashen (1973) argues for a terminal age earlier than puberty. While most authors appear to subscribe to an upper critical period age between 5 to 15, some reject the notion of a critical period - see, in particular, Bialystok and Hakuta (1999), Hakuta, Bialystok and Wiley (2003) and Wiley, Bialystok, and Hakuta (2004).

Critical periods have been assessed using three types of studies: individual case studies, experimental laboratory studies, and analyses of large survey/census data sets. The focus in the case studies and experimental laboratory work has largely been on whether second language learners achieve native-like outcomes, and detailed test instruments have been employed. However, both individual case studies and experimental laboratory studies have been based on small, select, samples. ${ }^{3}$

In contrast, Bialystok and Hakuta (1999) provide a study of cross-tabulations from the 1990 US Census covering tens of thousands of observations. They focus on Spanish and Chinese speaking immigrants in New York, with ages of arrival (or ages of onset) between zero and 70+, who have 10 years or more residence in the US (or equivalently, exposure to English). ${ }^{4}$ The analyses were conducted disaggregated by level of education, with educational attainment being shown to be positively related to English proficiency. They show that English proficiency declines more or less continuously with age at arrival. This evidence was interpreted as rejecting the critical period hypothesis.

Hakuta, Bialystok and Wiley (2003) extend the analyses of the 1990 US Census data by Bialystok and Hakuta (1999), largely though covering additional States, and by a more rigorous statistical testing of the model. A modified set of analyses is presented in Wiley, Bialystok and Hakuta (2004), in response to a critique offered by Stevens (2004). Specifically, Hakuta, Bialystok and Wiley (2003) test statistically for changes in the mean English proficiency, and also for changes in the partial effect of age, at two possible critical points, immigration at age 15 and at age 20. A non-parametric (local regression) approach was also employed. In each instance the authors report evidence of gradual declines in English proficiency with age at arrival in the US. No evidence was found of a discontinuity "that is the essential hallmark of a critical period" (Hakuta, Bialystok and Wiley (2003, p.37)). Hakuta, Bialystok and Wiley (2003) thus reject the 
critical period hypothesis. Wiley, Bialystok and Hakuta (2004) use the one percent Public Use Microdata Sample from the 1990 Census to provide analyses by region of birth as well as by language spoken at home. They report that their earlier conclusions on the lack of support for the critical period hypothesis carry over to these analyses.

The various studies by Bialystok, Hakuta and Wiley, being based on US Census data, have many similarities with the research of sociologists and economists on the determinants of English language proficiency (see, for example, Stevens (1992), Espenshade and Fu (1997) and Chiswick and Miller (1995)(2008)). The distinguishing feature of the multivariate analyses conducted in these studies is the rich array of standardizing variables included in the statistical model, a feature intended to control statistically for a wide range of factors that influence language attainment. Hyltenstam and Abrahamsson (2003, p.559), for example, argue that "Among other factors, frequency and quality of input as well as identity issues seem to play an important role and interact with maturational constraints for the outcome even at a low age”.

As some of the additional variables considered in the research by Chiswick and Miller (1995)(2007a)(2008), Espenshade and Fu (1997) and Stevens (1992) may be related to age at immigration, their absence in the study by Hakuta, Bialystok and Wiley (2003) may either accentuate or attenuate the age at immigration effects on ultimate English proficiency. Thus, one of the contributions of the current paper is to ascertain the relevance of the critical period hypothesis within the more encompassing framework these authors propose. In addition, being based on data from the 2000 US Public Use Microdata Sample, which contains information on both age and time in the US in individual years rather than as intervals, it avoids one of the problems (the use of broad categories for key variables) that Stevens (2004) has raised as a criticism of Hakuta, Bialystok and Wiley (2003), and which Wiley, Bialystok and Hakuta (2004) were not able to fully overcome. Finally, an alternative approach to examining the critical period hypothesis is outlined. This approach offers a flexible, and intuitive, way of identifying any critical period in the age at arrival-English proficiency relationship.

The structure of the paper is as follows. Section II outlines the approach taken in the recent work by Chiswick and Miller (1995, 2007a, 2008). Developed from an economics perspective, the model they propose has parallels with work in sociology (see, 
for example, Espenshade and Fu (1997) and Stevens (1992)), and is more encompassing than the model applied by Hakuta, Bialystok and Wiley (2003). Section III provides information on the data set used in the empirical work, the one percent Public Use Microdata Sample from the 2000 US Census. Section IV contains the analyses of the relation between self-reported proficiency in spoken English and age at migration. Tests of robustness are offered through separate analyses by gender, by Mexican/non-Mexican origin, and for immigrants according to whether their mother tongue is close to, or distant from, English. Section V offers concluding comments.

\section{AN ECONOMIC MODEL OF ENGLISH LANGUAGE PROFICIENCY}

Chiswick and Miller (1995, 2007a, 2008) develop a conceptual framework that is used to account for variations in the English language proficiency of immigrants from non-English-speaking countries. ${ }^{5}$ It is organized around three broad concepts: exposure, efficiency, and economic incentives.

The exposure, efficiency and economic incentive variables will only be very briefly outlined here (Table 1), as they are not of primary interest for this study and serve merely to control statistically for effects which, if not taken into account, could bias the relationship between age at migration and English speaking proficiency. These control variables are highly statistically significant with their expected signs. They are discussed in detail in the fuller version of this study (Chiswick and Miller, 2007b).

Exposure to English can occur pre-migration or post migration. Given the data limitations of the Census, pre-migration exposure for immigrants from countries other than the English-speaking developed countries is measured by a variable COLONY, which is unity if the country of birth is, or had been, a colony of the US or the UK. Those from former colonies are expected to be more proficient in English.

Post-migration exposure to English is measured by duration in the US and the intensely of exposure per unit of time in the US. Duration (years since migration or YSM) is measured by the year 2000 minus the year the immigrant came to the US to stay. It is expected to have a positive effect that diminishes with duration. A proxy measure for interrupted stays is whether the immigrants who came to the US more than 5 years ago lived outside the US five years ago (ABROAD5). The intensity of exposure is measured 
by the extent to which the immigrant lives in a minority language enclave (CONC, negative effect), by the immigrant's marital status (MARRIED), and by the age structure of the children living in the household (Chiswick, Lee and Miller, 2005a, b).

Efficiency refers to the ability to convert exposure into language learning. There are four important measurable efficiency factors that can influence the development of dominant language skills among immigrants. One is age at migration (AAM), the variable of primary interest for the study. A second is educational attainment, as those with more schooling are expected to be more proficient (EDUC). They may have an inherently higher level of ability for learning, or may have acquired learning skills in school. Third is refugee status (REFUGEE), as refugees tend to be individuals who are less favorably self-selected for a successful adjustment in the destination than are family motivated or employment-based migrants (Cortes, 2004). Refugees are expected to be less proficient. The fourth is "linguistic distance". The quantitative measure of the linguistic distance between English and a myriad of other (non-Native American) languages used here is developed in Chiswick and Miller (2005). It is based on the difficulty Americans have learning other languages and the assumption of symmetry, that is, if Americans have greater difficulty learning Korean than Dutch, then Korean speakers will have greater difficulty than Dutch speakers in learning English.

The economic incentives for acquiring destination language proficiency are central to the model of language acquisition. Finding empirical counterpoints, however, is difficult. Two sets of factors will be important, the expected improvements in economic outcomes (e.g., wages and employment) and the length of time these benefits are likely to be received. As there are strong links between educational attainment and the economic (wage and employment) returns from becoming proficient, the individual's level of schooling may also serve as a proxy for the expected economic benefits from becoming proficient (Chiswick and Miller, 2003, 2007a).

The period of time in the destination over which the benefits are likely to be received is related to the propensity for return migration. This is measured by the geographic distance between the country of origin and the nearest large port of entry into the United States (New York, Miami, Los Angeles). A different measure is used when the analysis is performed solely for immigrants fro Mexico. 
Hence, the empirical counterpart of the conceptual framework developed by Chiswick and Miller (1995, 2007a, 2008) that is the basis for the analysis that follows is:

LANG $=\mathrm{f}($ Age at Migration, Educational Attainment, YSM, YSMSQ, ABROAD5, MARRIED, Children, NON-MET, SOUTH, MILES, MILESQ, Linguistic Distance, CONC, COLONY, REFUGEE)

The variables, mnemonics and hypothesized effects are defined briefly in Table 1 and in Appendix A, and in detail in Chiswick and Miller (2007b).

\section{THE 2000 US CENSUS DATA}

The data for the estimations presented in Section IV are from the US 2000 Census of Population, Public Use Microdata Sample, and are for the 1 percent sample of the foreign-born adult (25-64 year old) men and women from non-English speaking countries. ${ }^{6}$ The issues surrounding language choice are most acute for this age group. Table 2 presents information on the frequency distribution for age at migration for the six groups featured in the analyses that follow.

The analyses are performed separately by gender, and overall and separately for immigrants from Mexico and all other countries. Mexico is the largest single source country, providing over one-third of the men and women in the sample. Moreover, Mexican migrants have much lower levels of skills (among adult males they have 8 years of schooling compared to 13 years for other immigrants) and a much greater proportion of illegal aliens than migrants from other countries. They may be of special interest for these reasons.

The 2000 US Census has three questions on language. The first is a streaming question: "Does this person speak a language other than English in the home?". Individuals responding YES were asked two further questions. "What is this language?", with only one language being coded. And, "How well does this person speak English?”. Individuals were asked to indicate one of four levels of proficiency: very well; well; not well; not at all. Five categories of English use/proficiency may be formed, namely: (i) speaks only English at home; speaks a language other than English at home and speaks English (ii) very well; (iii) well; (iv) not well; (v) not at all. 
Two broad measures of English skills have been constructed from this information for use in empirical work. The first is a polychotomous (five categories) variable. The second is a binary measure, which is set equal to one for individuals categorized as "proficient in English", and is set to zero for those not proficient in English. For example, where the emphasis is on "native-like" language outcomes, those who speak only English at home, or if a language other than English is spoken in the home, the individual speaks English "very well”, might be categorized as proficient." Analyses presented in Chiswick and Miller (2008) suggest that the binary and polychotomous approaches to modeling English language proficiency offer similar insights. Given the focus in the current paper, the statistical analysis uses a dichotomous dependent variable where those who speak only English at home, or speak English "very well”, are considered proficient and all other groups are considered not proficient.

\section{TESTING THE CRITICAL PERIOD HYPOTHESIS}

The probit regression equations with the dichotomous dependent variable were computed separately by gender for all immigrants, immigrants from Mexico and immigrants from countries other than Mexico. The equations are reported and the partial effects of the explanatory variables are discussed in Chiswick and Miller (2007b), the longer version of this paper. It is noted that the data are consistent with all of the effects hypothesized above. Here the focus is on the effects of age at migration on English language proficiency. The age-at-migration data were entered into the model in the form of 64 dichotomous variables for individual ages. This is the most flexible approach to quantifying the relationship between English proficiency and age at migration. In the analyses presented here, the ages at migration of zero and one are used as the omitted group, and all other age groups are compared to this one. ${ }^{8}$ Figures 1 to 3 summarize the effects of age at migration on English language proficiency.

A number of striking patterns emerge in these figures.

First, proficiency in English declines monotonically with age at migration for the three birthplace groups.

Second, within country of origin, the patterns are very similar for men and women. 
Third, the variability in the proportion proficient in English across adjacent ages at migration is greater the older the age at migration. This is presumably due to greater sampling variability because of the smaller sample sizes at older ages at migration (Table 2). Few immigrants come in middle age or older. For example, among male immigrants in the sample under study, there were 3,829 who arrived at age 24, while there were only 255 who arrived at age 50. The year to year variability is even greater for Mexican than for other immigrants because of the smaller sample sizes at older ages for the former.

Fourth, among non-Mexican immigrants, the decline in proficiency with age at migration is initially shallow (up to age 8), then exhibits a sharper decline that gradually diminishes, until the marginal effect of age at migration disappears after age 40. On the other hand, among Mexican immigrants there is a sharp decline in proficiency with age at migration until about age 16, after which there is little change. These patterns suggest important differences between immigrants from Mexico and all other countries.

It appears that if a "critical period" for language learning is defined as an age at which there is a sharp decline in the ability of immigrants to obtain proficiency in speaking English, no such critical period exists. The acquisition of English language proficiency (as defined above) declines with an increase in the age at migration. The pattern of decline is sharper for Mexican immigrants until about a migration age of 16 years, after which there is no important difference by age at migration. Among other immigrants, the decline is more gradual and disappears beyond an age at migration of 40 .

As a result, other variables the same, the proficiency rate among Mexican and other immigrants is about the same for those who immigrated at age zero or one (about 80 percent proficient), lower thereafter for Mexican immigrants, until a parity is reached at about 30 percent for any age at arrival of about 40 and older ages.

Note that these analyses also show that there are ages at migration where the English proficiency of immigrants does not differ significantly from that of the benchmark group of very early arrivers, and that thresholds exist beyond which the age at migration effects are statistically significant at the 5 percent level. These thresholds are denoted by "T" in the diagrams, with " $m$ " and "f" in parentheses for males and females, respectively. For males these are age 6 for the total sample, age 9 for immigrants from countries other than Mexico, and age 6 for immigrants from Mexico. For females, the 
threshold ages are, in each instance, one year earlier than is the case for males. Using a 1 percent level of significance lengthens the apparent period from the benchmark to a significant difference by only one year in most instances. There are, however, no adjacent age categories where the estimated effects in the language model differ from each other which can be considered the purest interpretation of the critical period hypothesis.

The data for immigrants from countries other than Mexico can be disaggregated according to how difficult it might be for them to learn English. The disaggregation by ease or difficulty of learning English is on the basis of the linguistic distance of the mother tongue from English. ${ }^{9}$ Two, approximately equal-sized groups, were formed by using a cut-off measure of linguistic distance of 0.5 (or linguistic score of 2), which is the score for Polish, Czech and Thai. These and languages with lower scores (e.g., Greek, Japanese, Hindi, Arabic, Mandarin) are in the group with mother tongues more distant from English. Languages with higher scores (e.g., Danish, Portuguese, Spanish, Italian) are in the group with mother tongues closer to English.

The relationships between age at migration and English proficiency for these groups are presented in Figures 4 and 5, with the regression equations reported in Chiswick and Miller (2007b). Figure 4 is for immigrants who have mother tongues distant from English and who, as a consequence, might be expected to find learning English more difficult. Figure 5 is for immigrants who have mother tongues close to English, and who therefore might be expected to find it easier to learn English.

Figures 4 and 5 have the same general features as Figures 1 to 3. Thus, there is a negative relationship between English proficiency and age at migration for both immigrants with mother tongues close to English and for those with mother tongues distant from English. For immigrants with mother tongues distant from English, the gradient of the relationship in Figure 4 is quite steep over the early ages at migration. For immigrants with mother tongues close to English, the decline in English proficiency with an older age at migration is initially modest, and it is therefore this group which generated the relatively flat profile of Figure 3. Thus, there is an interaction between linguistic distance and age at migration in an analysis of language learning. Age at migration matters more where the mother tongue implies it is more difficult to learn EnglishNote that the disaggregation by linguistic distance results in more variability in 
the predicted effects, owing to the smaller sample sizes used in the estimations. Nevertheless, the patterns that emerge are clear, and remarkably consistent for males and females.

\section{CONCLUSION}

The analyses of the effects of age at migration on the English speaking proficiency of immigrants in the US from non-English speaking countries reported here are used to test the critical period hypothesis. They are conducted by gender for immigrants from all countries, from Mexico, and for immigrants from other countries, and within the latter group, those with mother tongues close to English and those with mother tongues distant from English. Proficiency in self-reported spoken English is shown to decline more-or-less monotonically with age at migration.

The analyses could not, however, identify an age at which there is a sharp decline in the ability of immigrants to acquire proficiency in speaking English. While the differences in English proficiency at ages of migration sufficiently far apart are statistically significant, the differences in English proficiency for adjacent age-atmigration categories do not differ significantly. These findings carry across to each of the sub-sample analyses. They are remarkably similar for males and females.

A critical period, defined with reference to a discontinuity, that is, a sharp, statistically significant difference in English proficiency with respect to adjacent ages at migration, does not appear to exist for self-reported spoken English among immigrants in the US. 
Table 1

Definitions of Variables Used in the Statistical Analysis of English Proficiency Among Immigrants from Non-English Speaking Countries, 2000 US Census

\begin{tabular}{|c|c|}
\hline Variable Name/ Mnemonics & Description (Hypothesized sign in parentheses) \\
\hline LANG & $\begin{array}{l}\text { Proficient in English if speak only English at home, or if } \\
\text { speak another language, speak English very well. }\end{array}$ \\
\hline Educational Áttainment & Years of education. $(+)$ \\
\hline Age at Migration & Age minus years of residence in the US. (-) \\
\hline YSM (Years Since Migration) & $\begin{array}{l}\text { The number of years since the immigrant first arrived in } \\
\text { the US to stay. }(+)\end{array}$ \\
\hline YSMSQ & The square of YSM. (-) \\
\hline ABROAD5* & $\begin{array}{l}\text { Lived abroad five years ago for those who immigrated } \\
\text { more than } 5 \text { years ago. (-) }\end{array}$ \\
\hline MARRIED* & The individual is married, with spouse present. (?) \\
\hline Children* & $\begin{array}{l}\text { Has a child aged under } 6 \text {; Has a child aged 6-17; Has } \\
\text { children under } 6 \text { and 6-17 years of age. (?) }\end{array}$ \\
\hline EDUC & Years of schooling completed $(+)$ \\
\hline NON-MET* & Lives outside the metropolitan areas. (-) \\
\hline SOUTH* & $\begin{array}{l}\text { Lives in Alabama, Arkansas, Delaware, District of } \\
\text { Columbia, Florida, Georgia, Kentucky, Louisiana, } \\
\text { Maryland, Mississippi, Missouri, North Carolina, } \\
\text { Oklahoma, South Carolina, Tennessee, Texas, Virginia } \\
\text { or West Virginia. (?) }\end{array}$ \\
\hline MILES & $\begin{array}{l}\text { Direct line distance between the major city in the } \\
\text { immigrant's country of origin and either New York, } \\
\text { Miami, or Los Angeles (whichever is the shortest), in } \\
\text { thousands of miles. }(+)\end{array}$ \\
\hline MILESQ & The square of MILES. (-) \\
\hline Linguistic Distance & $\begin{array}{l}\text { A measure of the difficulty of learning a foreign } \\
\text { language for English-speaking Americans. (-) }\end{array}$ \\
\hline CONC & $\begin{array}{l}\text { A measure of minority language concentration, given by } \\
\text { the percentage of the population aged eighteen to sixty- } \\
\text { four in the region in which the individual lives, who } \\
\text { report speaking the same non-English language as the } \\
\text { individual. For analyses for Mexico, the distance is } \\
\text { from the capital of their state of residence to Tijuana or } \\
\text { Ciudad Juarez.(-) }\end{array}$ \\
\hline COLONY* & $\begin{array}{l}\text { Country of origin is a current or former colony of the } \\
\text { US or the UK (excludes Puerto Rico). }(+)\end{array}$ \\
\hline REFUGEE* & $\begin{array}{l}\text { Constructed using information on age, age at arrival, and } \\
\text { birthplace, to identify the major sources of post-WWII } \\
\text { refugees to the US. (-) }\end{array}$ \\
\hline
\end{tabular}

Note: $*$ dichotomous variable. 
Table 2

Frequency Distribution for Age at Immigration, By Gender and Mexican/Non-Mexican Origin, 2000

\begin{tabular}{|c|c|c|c|c|c|c|}
\hline \multirow{2}{*}{$\begin{array}{l}\text { Age at } \\
\text { Migration } \\
\text { (Year) }\end{array}$} & \multicolumn{3}{|c|}{ Males } & \multicolumn{3}{|c|}{ Females } \\
\hline & All & Mexico & $\begin{array}{c}\text { Non- } \\
\text { Mexico }\end{array}$ & All & Mexico & $\begin{array}{c}\text { Non- } \\
\text { Mexico }\end{array}$ \\
\hline$<5$ & 3.98 & 3.44 & 4.29 & 4.39 & 4.64 & 4.28 \\
\hline $5-9$ & 4.80 & 4.03 & 5.23 & 4.98 & 4.97 & 4.99 \\
\hline $10-14$ & 7.29 & 8.49 & 6.63 & 6.87 & 8.45 & 6.20 \\
\hline $15-19$ & 18.13 & 28.12 & 12.60 & 14.69 & 21.76 & 11.68 \\
\hline $20-24$ & 21.39 & 23.94 & 19.97 & 22.32 & 24.42 & 21.43 \\
\hline $25-29$ & 18.26 & 15.00 & 20.07 & 18.65 & 15.58 & 19.94 \\
\hline $30-34$ & 11.04 & 7.73 & 12.88 & 11.28 & 8.58 & 12.42 \\
\hline $35-39$ & 6.61 & 4.43 & 7.82 & 6.95 & 5.01 & 7.78 \\
\hline $40-44$ & 4.07 & 2.45 & 4.96 & 4.45 & 2.98 & 5.07 \\
\hline $45-49$ & 2.37 & 1.25 & 2.99 & 2.69 & 1.86 & 3.04 \\
\hline $50+$ & 2.05 & 1.12 & 2.56 & 2.73 & 1.72 & 3.16 \\
\hline Total & 100.00 & 100.00 & 100.00 & 100.00 & 100.00 & 100.00 \\
\hline Mean & 23.917 & 21.795 & 25.093 & 24.501 & 22.397 & 25.391 \\
\hline $\begin{array}{l}\text { Standard } \\
\text { Deviation }\end{array}$ & 10.805 & 9.370 & 11.353 & 11.295 & 10.411 & 11.535 \\
\hline $\begin{array}{l}\text { Sample } \\
\text { Size }\end{array}$ & 85,865 & 31,864 & 54,001 & 83,832 & 25,832 & 58,000 \\
\hline
\end{tabular}


Figure 1

Effects of Age at Migration on English Proficiency, Immigrants from non-English Speaking Countries, by Gender

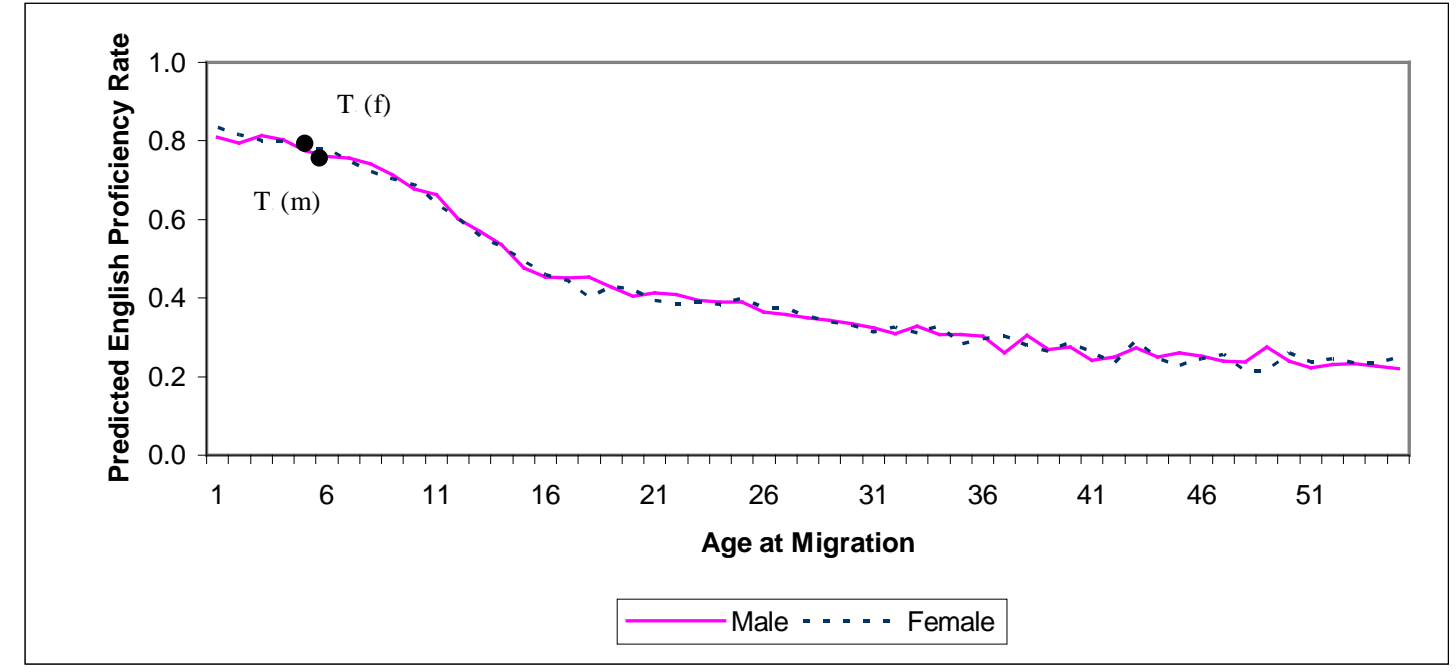

Source: Authors’ calculations from 2000 US Census, 1\% Public Use Microdata Sample. 
Figure 2

Effects of Age at Migration on English Proficiency, Immigrants from Countries Other than Mexico, by Gender

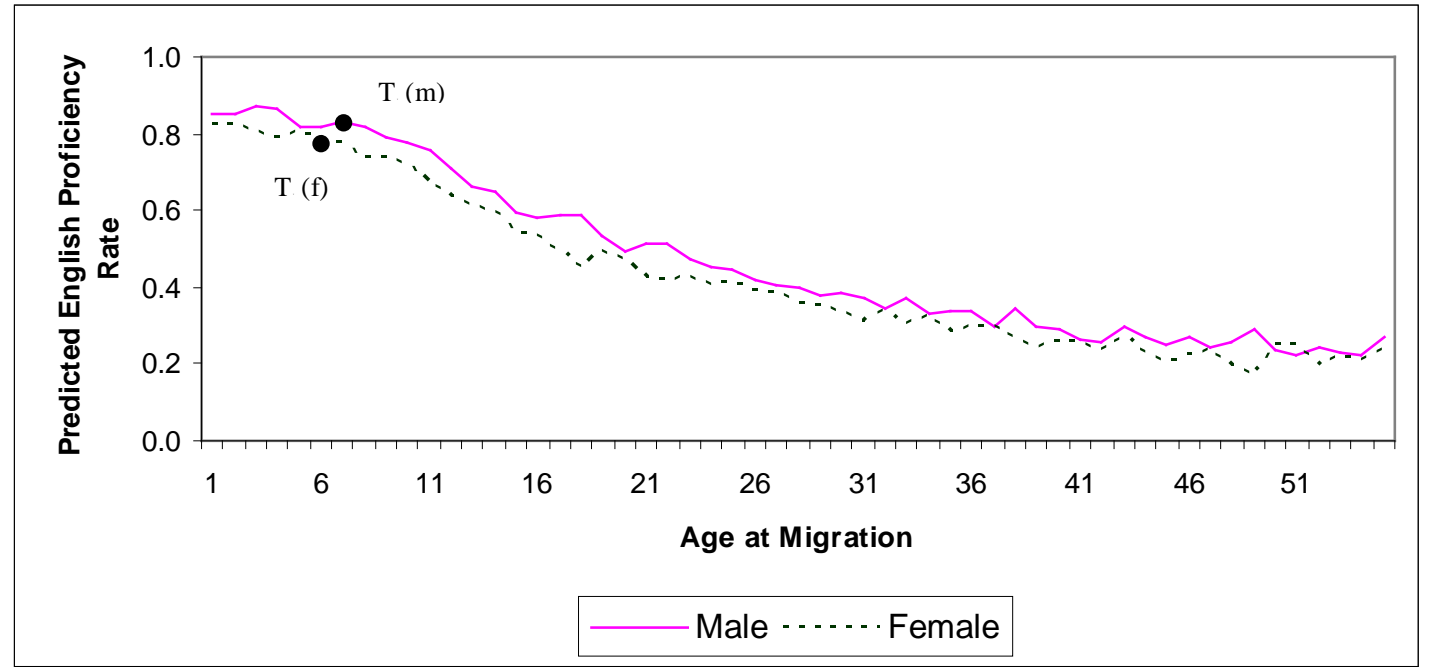

Source: Authors’ calculations from 2000 US Census, 1\% Public Use Microdata Sample. 
Figure 3

\section{Effects of Age at Migration on English Proficiency, Immigrants from Mexico, by Gender}

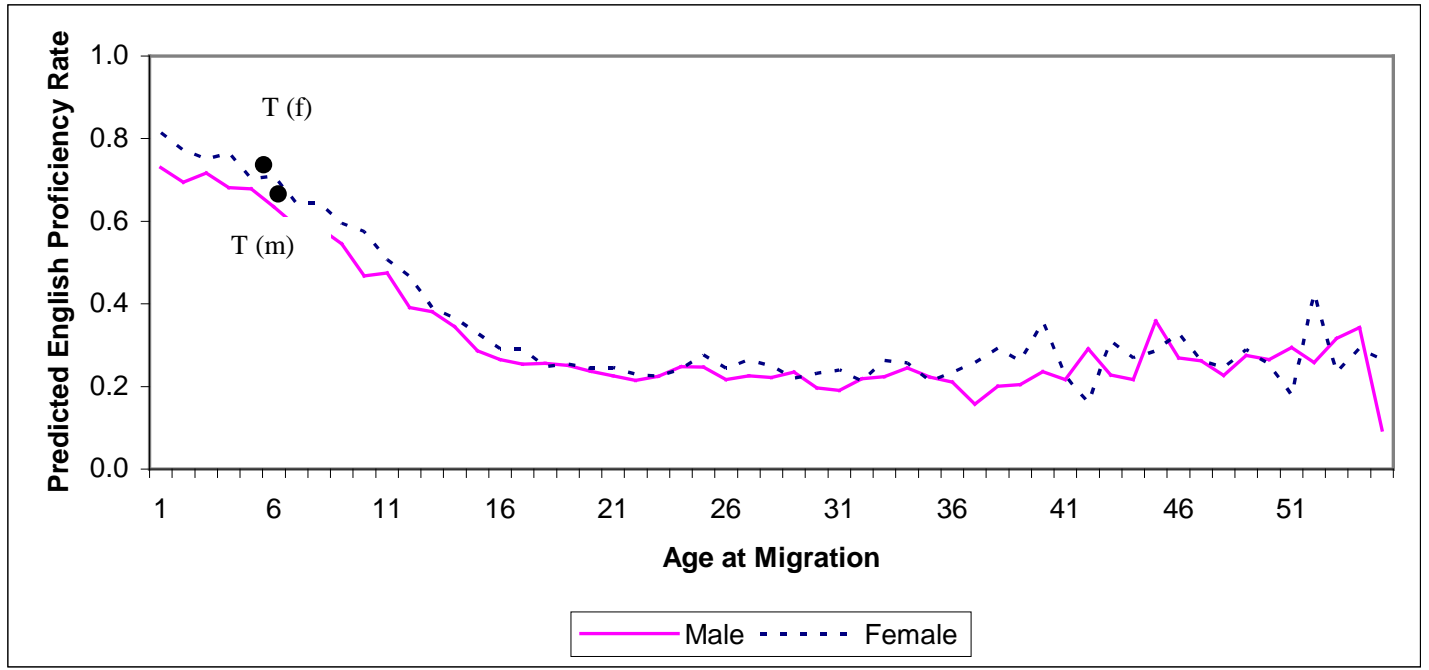

Source: Authors’ calculations from 2000 US Census, 1\% Public Use Microdata Sample. 
Figure 4

Effects of Age at Migration on English Proficiency, Immigrants from Countries other than Mexico with Mother Tongues Distant from English, by Gender

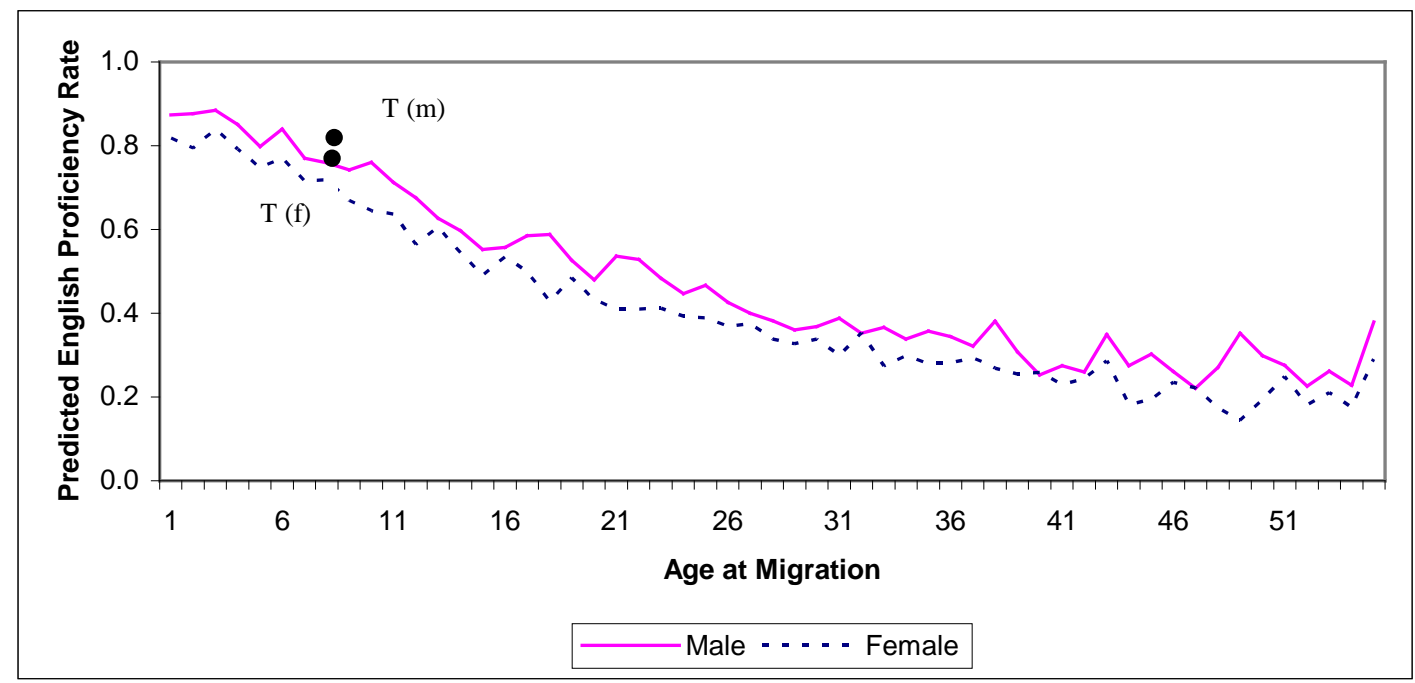

Source: Authors’ calculations from 2000 US Census, 1\% Public Use Microdata Sample. 
Figure 5

Effects of Age at Migration on English Proficiency, Immigrants from Countries other than Mexico with Mother Tongues Close to English, by Gender

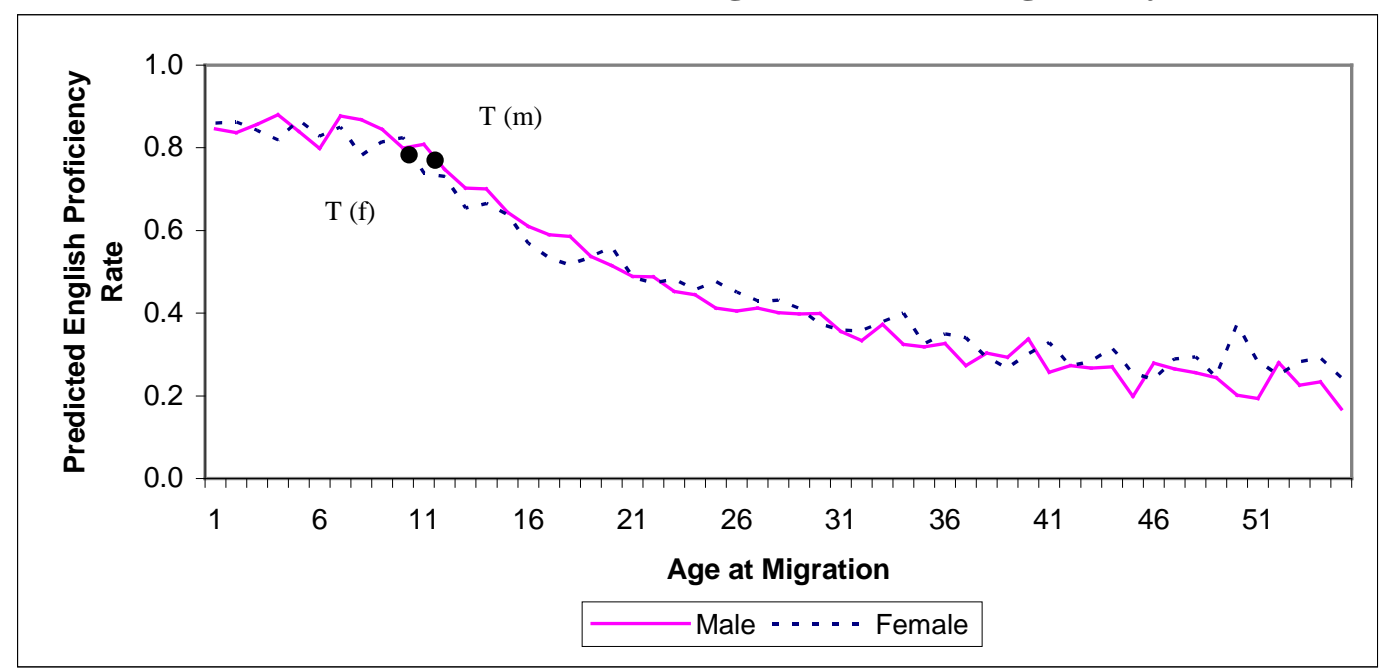

Source: Authors’ calculations from 2000 US Census, 1\% Public Use Microdata Sample. 


\section{ENDNOTES}

* A fuller version of this paper with the title "The Critical Period Hypothesis for Language Learning: What the 2000 US Census Says” is IZA Discussion Paper No. 2575 (January 2007) and is available from www.IZA.org. We thank Derby Voon for research assistance. Chiswick acknowledges research support from the Smith Richardson Foundation and the Institute of Government and Public Affairs, University of Illinois. Miller acknowledges financial assistance from the Australian Research Council.

${ }^{1}$ Older learners may be at an advantage in some areas (e.g., syntax), but this advantage is typically short-lived.

${ }^{2}$ See Hakuta, Bialystok and Wiley (2003) for a review of age-related changes in cognitive processes.

${ }^{3}$ See Bialystok (1997) for a critique of the evidence that supports the critical period hypothesis.

${ }^{4}$ While the US Census data contains only self-reported English speaking proficiency for those who use a language other than English at home, and the cross-tabulations used by Bialystok and Hakuta (1999) report the age and age-at-arrival information only in broad intervals rather than by year, these data have the advantage of a very large sample. Specifically, they analyzed data on 38,787 speakers of Spanish and 24,903 speakers of Chinese. In their subsequent study (Hakuta, Bialystok and Wiley, 2003), the sample sizes for these two groups were 2,016,317 and 324,444, respectively.

${ }^{5}$ This model has been applied successfully to study the destination language proficiency of immigrants in the US, Canada, Australia and Israel. See Chiswick and Miller (1995, 2007a, 2008).

${ }^{6}$ Immigrants from the main English-speaking countries (UK, Ireland, Canada, Australia, New Zealand and the Caribbean) are excluded for obvious reasons. Persons born in US Territories, such as Puerto Rico, are also excluded.

${ }^{7}$ Espenshade and Fu (1997) pool these two groups to form a single "very well" category.

${ }^{8}$ This is equivalent to testing whether the onset of the critical period commences at the age of two, which would be consistent with Lenneberg's (1967) work. Recognizing that others have argued for an earlier age at onset, the analyses were repeated using only age zero (born and migrated in the same year) as the omitted category. This did not change the conclusion in any material way.

${ }^{9}$ The 2000 US Census did not ask for mother tongue. The "mother tongue" used in this analysis has been inferred from the home language, and where only English is spoken at home, the languages of the country of origin. 


\section{REFERENCES}

Bialystok, Ellen, (1997). "The Structure of Age: In Search of Barriers to Second Language Acquisition”, Second Language Research, 13(2):116-137.

Bialystok, Ellen and Hakuta, Kenji, (1999). "Confounded Age: Linguistic and Cognitive Factors in Age Differences for Second Language Acquisition”, in D. Birdsong (ed.) Second Language Acquisition and the Critical Period Hypothesis, Lawrence Erlbaum Associates, Mahwah, New Jersey.

Chiswick, Barry R., Lee, Yew Liang and Miller, Paul W., (2005a). "Family Matters: The Role of the Family in Immigrants' Destination Language Acquisition”, Journal of Population Economics, 18(1):1-17.

Chiswick, Barry R., Lee, Yew Liang and Miller, Paul W., (2005b). "Parents and Children Talk: English Language Proficiency Within Immigrant Families”, Review of Economics of the Household, 3(3):243-268.

Chiswick, Barry R. and Miller, Paul W. (1995). "The Endogeneity Between Language and Earnings: International Analyses”, Journal of Labor Economics, 13(2): 246288.

Chiswick, Barry R. and Miller, Paul W. (2003) "The Complementarity of Language and Other Human Capital: Immigrant Earnings in Canada”, Economics of Education Review, 22:469-480.

Chiswick, Barry R. and Miller, Paul W., (2005) "Linguistic Distance: A Quantitative Measure of the Distance Between English and Other Languages”, Journal of Multilingual and Multicultural Development, 26(1):1-11.

Chiswick, Barry R. and Miller, Paul W. (2007a). The Economics of Language: International Analyses, Routledge, London.

Chiswick, Barry R. and Miller, Paul W. (2007b). "The Critical Period Hypothesis in Language Learning: What the 2000 US Census Says” IZA Discussion Paper No. 2575, January 2007.

Chiswick, Barry R. and Miller, Paul W. (2008). "Modelling Immigrants' Language Skills", Research in Labor Economic, 27. (forthcoming).

Cortes, Kalena E. (2004). 'Are Refugees Different from Economic Immigrants? Some Empirical Evidence on the Heterogeneity of Immigrant Groups in the United States', Review of Economics and Statistics, 86(2):465-480. 
Espenshade, Thomas J. and Fu, Haishan, (1997). "An Analysis of English Language Proficiency Among U.S. Immigrants," American Sociological Review, 62(April):288-305.

Hakuta, Kenji, Bialystok, Ellen and Wiley, Edward, (2003). "Critical Evidence: A Test of the Critical Period Hypothesis for Second-Language Acquisition”, Psychological Science, 14(1):31-38.

Hyltenstam, Kenneth and Abrahamsson, Niclas, (2003). "Maturational Constraints in SLA”, pp.539-588 in Catherine J. Doughty and Michael H. Long (eds.) The Handbook of Second Language Acquisition, Blackwell Publishing, Oxford.

Krashen, S., (1973). "Lateralization, Language Learning and the Critical Period: Some New Evidence”, Language and Learning, 23:63-74.

Larsen-Freeman, Diane and Long, Michael H. (1991). An Introduction to Second Language Acquisition Research, Longman, New York.

Lenneberg, Eric H., (1967). Biological Foundations of Language, John Wiley, New York.

Penfield, Wilder, and Roberts, Lamar, (1959). Speech and Brain Mechanisms, Princeton University Press, Princeton, New Jersey.

Scovel, Thomas, (2000). “A Critical Review of the Critical Period Research”, Annual Review of Applied Linguistics, 20: 213-223.

Stevens, Gillian, (1992). "The Social and Demographic Context of Language Use in the United States”, American Sociological Review, 57:171-185.

Stevens, Gillian, (2004). "Using Census Data to Test the Critical-Period Hypothesis for Second-Language Acquisition”, Psychological Science, 15(3):215-216.

Wiley, Edward, Bialystok, Ellen and Hakuta, Kenji, (2004). "New Approaches to Using Census Data to Test the Critical-Period Hypothesis for Second-Language Acquisition”, Psychological Science, 16(3):341-343. 


\section{APPENDIX A}

\section{DEFINITIONS}

Data Source: 2000 Census of Population of the United States, Public Use Microdata Sample, 1 percent sample of the foreign born.

Definition of Population: Foreign-born men and women aged twenty-five to sixty-four, born in countries other than the main English-speaking countries (UK, Ireland, Canada, Australia, New Zealand and the English-speaking Caribbean), territories of the United States, at sea or born abroad of American parents. Only residents of the 50 States and the District of Columbia are considered.

English Language Fluency (LANG): LANG is set equal to one for individuals who speak only English at home, or, if a language other than English is spoken in the home, who speak English "very well". The variable is set to zero where a language other than English is spoken in the home and the respondent speaks English either "well", "not well" or "not at all."

Age at Migration (AAM): AAM is computed as 2000 minus year the immigrant came to the US to stay.

For the definitions and means and standard deviations of the statistical control variables, see Chiswick and Miller (2007b). 